\title{
Aetiology of Ludwig van Beethoven's hearing impairment: hypotheses over the past 100 years - A systematic review
}

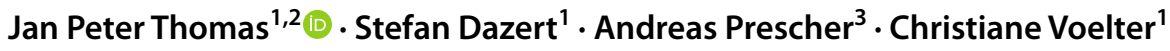

Received: 7 October 2020 / Accepted: 28 October 2020 / Published online: 23 November 2020

(c) The Author(s) 2020

\begin{abstract}
Objectives Even 250 years after Beethoven's birth, the irrevocable cause of his hearing impairment remains unclear despite multiple publications by different professional groups. This study aimed to analyse the development of the most likely aetiologies during the last 100 years by a systematic review of the relevant medical literature.

Methods A systematic review of medical literature in PubMed ${ }^{\circledR}$, PubMed Central ${ }^{\circledR}$, and Web of Science ${ }^{\circledR}$ for the period 1920-2020 was conducted. Medical publications between 1920 and 1935 were additionally searched manually by review of reference lists. Studies were eligible when a statement regarding the most likely aetiology of the hearing loss of Beethoven was the aimed objective of the publication.

Results 48 publications were included. The following aetiologies were supposed: otosclerosis $(n=10)$, syphilis $(n=9)$, Paget's disease $(n=6)$, neural deafness $(n=5)$, immunopathy with inflammatory bowel disease, neural deafness with otosclerosis, sarcoidosis or lead intoxication $(n=2)$, and systemic lupus erythematosus, trauma, labyrinthitis or inner ear disease $(n=1)$. There is an ongoing effort with a mean publication frequency in this topic of 0.48/year. From 1920 to 1970 , otolaryngologists were the group with the highest interest in this field (67\%), whereas since 1971 most authors have belonged to non-otolaryngologic subspecialities (81\%).

Conclusion Over the past 100 years, otosclerosis and syphilis were predominantly supposed to be the underlying causes. The hypothesis of syphilis—although rejected for a long time—-has had a remarkable revival during the past 20 years. Regarding the outcome following therapeutic intervention by cochlear implantation, the differential diagnosis of neural deafness would be relevant today.
\end{abstract}

Keywords Beethoven $\cdot$ Deafness $\cdot$ Hearing loss $\cdot$ Aetiology $\cdot$ Cause

\section{Introduction}

The hearing impairment of the composer Ludwig van Beethoven is one of the best-known cases of hearing loss among historical artists. It has attracted great interest over centuries

Jan Peter Thomas

jan.thomas@rub.de

1 Department of Otorhinolaryngology, Head and Neck Surgery, Katholisches Klinikum, Ruhr University Bochum, Bleichstr. 15, 44787 Bochum, Germany

2 Department of Otorhinolaryngology, Head and Neck Surgery, St.-Johannes-Hospital, Academic Teaching Hospital of the University of Münster, Johannesstr. 9-17, 44137 Dortmund, Germany

3 Institute of Molecular and Cellular Anatomy, RWTH Aachen University, Wendlingweg 2, 52057 Aachen, Germany as one might speculate that perfect hearing is essential to be able to create musical masterpieces like Beethoven did. Ludwig van Beethoven represents one of the best examples that the creation of ingenious musical masterpieces does not necessarily require an intact auditory feedback loop [1]. However, analyses of compositions from different periods of his life might reflect the influence of a high-frequency hearing loss at the beginning of his hearing impairment, leading to a diminished usage of high pitches in his compositions at this period of time [2]. Several controversial publications have dealt with the impact of Beethoven's impaired hearing status onto his compositional work from a musicological point of view in the past years [3, 4].

From the medical point of view, the scientific interest mainly focuses on the aetiology of his hearing impairment which is still the source of ongoing controversial scientific discussions on whether Beethoven might have benefitted 
from modern concepts of hearing rehabilitation such as cochlear implantation, which is today's treatment of choice in subjects with severe to profound hearing loss.

Therefore, the aim of this study was (1) to create a systematic review of the medical literature listed in medical databases over the past 100 years on the aetiology of Beethoven's hearing loss and (2) to critically discuss the pros and cons of the most frequently stated diagnoses.

To evaluate the aetiology of Beethoven's hearing loss, one mainly has to rely on contemporary primary sources. The medical history can be reconstructed by letters of the composer, his conversational books and documents from his physicians, biographers and other contemporaries. Results of medical examinations are documented in the protocol of the post-mortem examination in 1827 and additionally by a more recent analysis of the bone fragments of his skull in 1985 and 2005 and of his hair in 2000 [5-7].

\section{Presentation of the hearing loss in the primary literature}

Ludwig van Beethoven was born in December in 1770 in Bonn, Germany (the official baptism date was December 17th) and died on March 26th in 1827 at the age of 56 in Vienna, Austria. The first note of a hearing impairment was mentioned by the composer himself in two letters to his friend F. G. Wegeler written on June 29th and November 16th in 1801:

"That malicious demon, however, bad health, has been a stumbling-block in my path; my hearing during the last three years has become gradually worse $[\ldots]$.

My ears are buzzing and ringing perpetually, day and night. I can with truth say that my life is very wretched; for nearly 2 years past I have avoided all society, because I find it impossible to say to people, I am deaf! In any other profession this might be more tolerable, but in mine such a condition is truly frightful [...].

I hear none of the high notes of instruments or singers. [...] I often can scarcely hear a person if speaking low; I can distinguish the tones, but not the words, and yet I feel it intolerable if anyone shouts to me $[\ldots]$ "

"The ringing and buzzing in my ears have certainly rather decreased, particularly in the left ear, in which the malady first commenced, but my hearing is not at all improved; in fact I fear that it is become rather worse [...]" [8]

Herein, Beethoven gave a detailed description of his hearing impairment which started in the high frequencies with a progressive hearing loss initially affecting the left ear more than the right ear. Besides, he complained about a loss of sound discrimination and permanent tinnitus and showed signs of a positive recruitment.

Also in 1802, Beethoven mentioned his hearing impairment in the "Heiligenstädter Testament", a letter to his brothers Kaspar Karl und Johann from 1802:

"[...] But you must remember that six years ago I was attacked by an incurable malady [...] I was yet obliged early in life to isolate myself, and to pass my existence in solitude. If I at any time resolved to surmount all this, oh! how cruelly was I again repelled by the experience, sadder than ever, of my defective hearing!-and yet I found it impossible to say to others: Speak louder; shout! for I am deaf! [...].

Completely isolated, I only enter society when compelled to do so. I must live like an exile.

My intelligent physician recommended me to spare my hearing as much as possible, which was quite in accordance with my present disposition, though sometimes, tempted by my natural inclination for society, I allowed myself to be beguiled into it. But what humiliation when any one beside me heard a flute in the far distance, while I heard nothing, or when others heard a shepherd singing, and I still heard nothing! [...].

Ah! how could I possibly quit the world before bringing forth all that I felt it was my vocation to produce? And thus I spared this miserable life-so utterly miserable that any sudden change may reduce me at any moment from my best condition into the worst [...].

My brothers Karl and Johann, as soon as I am no more, if Professor Schmidt be still alive, beg him in my name to describe my malady, and to add these pages to the analysis of my disease, that at least, so far as possible, the world may be reconciled to me after my death.[...].

I joyfully hasten to meet death. If he comes before I have had the opportunity of developing all my artistic powers, then, notwithstanding my cruel fate, he will come too early for me, and I should wish for him at a more distant period; but even then I shall be content, for his advent will release me from a state of endless suffering. Come when he may, I shall meet him with courage. Farewell! [...] [8]

In 1802, the substantial impact of the progressive hearing loss on his mental state was already described. Social isolation, obvious signs of depression and suicidal tendencies were found. Moreover, Beethoven explicitly asked the medical posterity to figure out the aetiology of his hearing loss in this document. 
According to these most cited documents, Beethoven's hearing loss started in 1796 at the age of 26. In the subsequent years, his hearing thresholds deteriorated so that Beethoven began to use ear trumpets in 1813 which were constructed for him by J. N. Mälzel. Another tool to alleviate the hearing impairment-however also with limited benefits - was a resonating plate which was placed on the piano and reflected the soundwaves [9].

In 1814, the composer Louis Spohr attributed a highgrade hearing loss to Beethoven. However, an oral conservation was still possible in 1815 by speaking into the left ear of the composer [10], while Beethoven seemed to suffer from a more progressive hearing loss on the right ear during the course of the disease. Due to the ongoing progress of the hearing loss, Beethoven started to use conversation books for communication in 1818. In January 1819, the poet P. D. A. Atterboom described Beethoven as deaf as a block, and in May 1824 Beethoven did not even hear the frenetic jubilation at the premiere of his 9th symphony anymore, and had to be turned over by a singer to receive the applause of the audience [10].

The protocol of the autopsy which was performed 1 day after his death on March 27th in 1827 by the assistant of the Institute of Pathology in Vienna J. Wagner reveals some details regarding the ear and the cochlear nerves:

"The external auditory canal appeared to be lined with glistening cutaneous scales; this was especially marked near the concealed tympanic membrane. The Eustachian tube was very thickened and its mucosa rugose and rather narrowed at the bony part. The mastoid process was large and not marked off by any groove; its cells were conspicuous and lined by a highly-vascular mucosa. The whole of the petrous portion of the temporal bone, showing large vessels, was similarly well supplied with blood, especially in the region of the cochlea, the spiral lamina which seemed slightly reddish."

The facial nerves were of considerable thickness; the auditory nerves on the other hand shrunken and without pith; the accompanying auditory arteries were of a calibre of a crow-quill, and of cartilaginous consistency. The left auditory nerve, much the thinner, arose by three very thin, greyish roots; the right by one root, stronger and pale white [...]. The vault of the skull showed great tightness throughout and a thickness of about half an inch." (Fig. 1) [10]

However, there is no description of the middle ear structures available. According to G. Breuning, physician and son of a long-time friend of Beethoven, the temporal bones of the composer were stored in a jar for further examination after autopsy at the Institute of Anatomy at

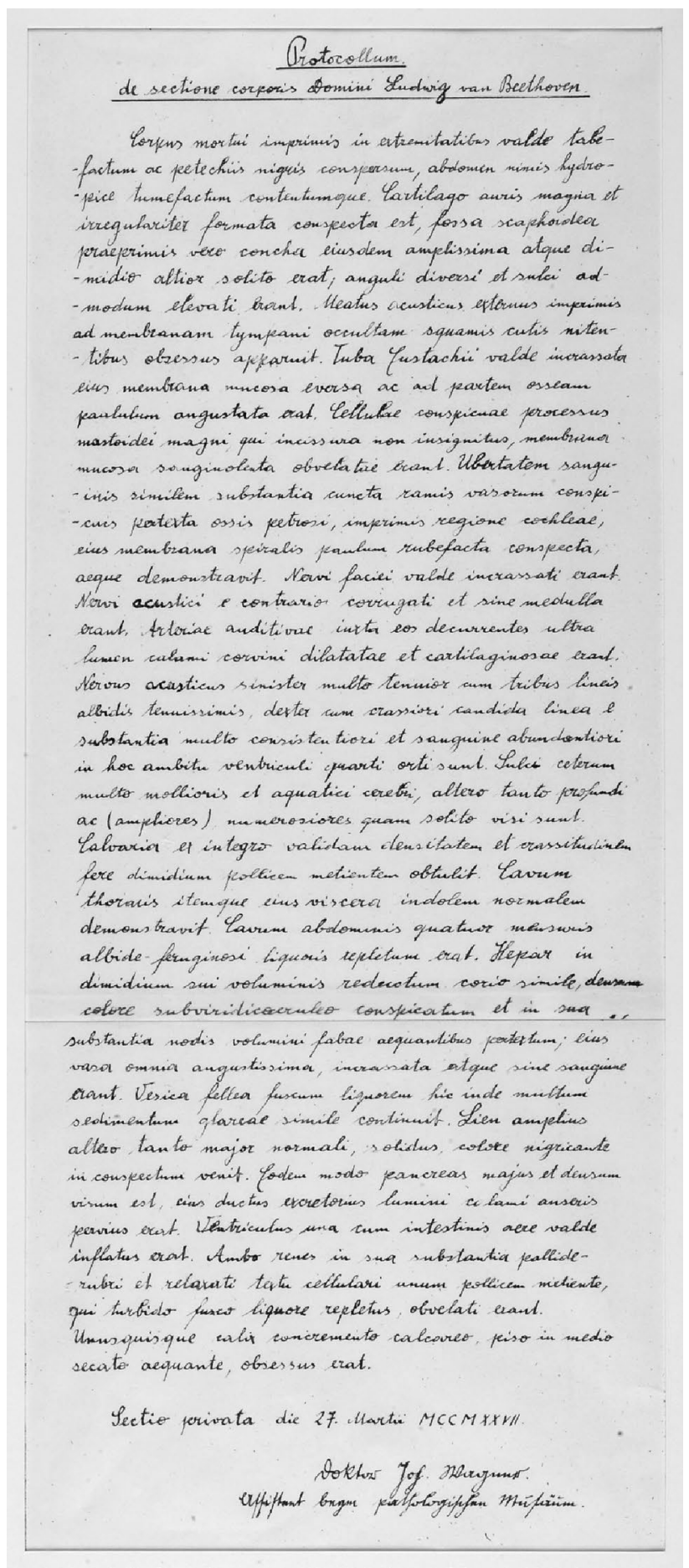

Fig. 1 Postmortem protocol of the autopsy of L. v. Beethoven performed by Dr. J. Wagner (reprint with kind permission of the Pathological-Anatomical Collection of the Medical University of Vienna, Austria)

the University of Vienna because the anatomist J. Hyrtl (1810-1894) stated that he had still seen them on the desk of the dissection attendant A. Datter [11]. However, 
according to further information at a later stage, they have been lost without any hint until today.

Beethoven himself and his physicians associated his hearing loss with his lifelong abdominal problems resulting in diarrhea, impaired digestion, and abdominal colics first mentioned at the age of 25 :

"The chief cause of this infirmity proceeds from the state of my digestive organs, which, as you know, were formerly bad enough, but have latterly become much worse, and being constantly afflicted with diarrhea, has brought on extreme weakness. my hearing became worse, and my digestion continued in its former plight. [...] I suffered from most dreadful spasms, and sank back into my former condition. digestive pills four days ago, and a tea for my ears. I certainly do feel better and stronger" [8].

Other diseases temporally associated with the beginning of the hearing loss were an unspecified "dangerous illness [in 1796] which shock hits his hearing tools, from which time his deafness gradually increased" [10] and the description of the physician A. Weißenbach that "he once survived terrible typhoid; from this time on, the deterioration of his nervous system and probably also the embarrassing deterioration of his hearing are dated" [12].

In addition to the life-long abdominal problems, Beethoven also suffered from other diseases. According to several authors who try to place all of Beethoven's symptoms under one single umbrella, the other diseases might be partially related to his hearing loss. In young adult life, Beethoven suffered from an arthropathy and in 1821 from jaundice. A painful eye condition in 1823 lasting for about 6 months was by some classified as an inflammatory ocular disease. Hematemesis and epistaxis which he suffered from in 1824 and 1825 might have been a prelude to the terminal illness of liver cirrhosis with a chronic pancreatitis. In this context, at the end of 1826/beginning of 1827, Beethoven was affected by extensive ascites and tapped four times before his death in March 1827.

\section{Material and methods}

\section{Data extraction}

For a systematic review of the medical literature of the last 100 years on the aetiology of Beethoven's hearing impairment, a computer-based search of medical publications was performed following the PRISMA guidelines [13]. Due to the topic of the study, the search process had to be adapted to the particularities of a medical historical theme. Three electronic databases including PubMed ${ }^{\circledR}$, PubMed Central $^{\circledR}$, and Web of Science ${ }^{\circledR}$ were used. The search was carried out from January 1, 1920, to June 30, 2020. The applied search terms in PubMed ${ }^{\circledR}$ and PubMed Central ${ }^{\circledR}$ were "Beethoven" in conjunction with "1920:2020[dp]" AND "deafness" or "hearing loss". Search terms in Web of Science were "Beethoven* deafness" or "Beethoven* hearing loss". After deduplication, two independent reviewers separately screened for eligibility and in case of incongruency a third reviewer provided consent. Titles and, if available, abstracts were screened for inclusion or exclusion.

As a first step, publications which did not deal with the medical history of the composer Beethoven (e.g., Tmc1 Beethoven mouse model) were excluded; as a second step, publications written in other languages than English, German, Spanish, Italian and French were discarded; and as a third step, publications which did not deal with the aetiology of Beethoven's hearing loss were excluded. Then, the full-text versions of all publications that passed the screening were thoroughly evaluated. As a fourth step, further publications which do not deal with the aetiology of Beethoven's hearing loss were discarded. As a fifth step, publications which did not give a statement regarding the underlying cause of the hearing loss were excluded. Studies were considered eligible if they comprised the description of a single favoured aetiology or if a clear exclusion of a cause was at least one of the study aims.

Currently Pubmed ${ }^{\circledR}$ covers only medical literature at the earliest from 1936 to the present day. Therefore, to get complete access to all publications published in medical journals over the past 100 years, medical publications published between 1920 and 1935 were additionally searched manually by review of all reference lists of the above-mentioned eligible papers.

\section{Results}

The results of the literature retrieval process regarding the medical literature from 1920 up to now is illustrated in the flow diagram depicted in Fig. 2. After careful evaluation of the medical literature between 1936 and 2020, 38 medical publications on the cause of Beethoven's deafness met the eligibility criteria for inclusion in this critical review. Retrieval for eligible literature from 1920 to 1935 revealed a further ten publications. Hereby, 30 original/review articles, 13 historical notes, 3 letters to the editor, 1 conference paper, and 1 editorial note were included. The overall 48 eligible publications are chronologically listed in Table 1 including the type of article and the medical speciality of the first author. If there was more than one publication from the same author group favouring the same most likely aetiology, the results are listed in the same line to prevent distortion of the presented results. 
Fig. 2 Flowchart of literature retrieval

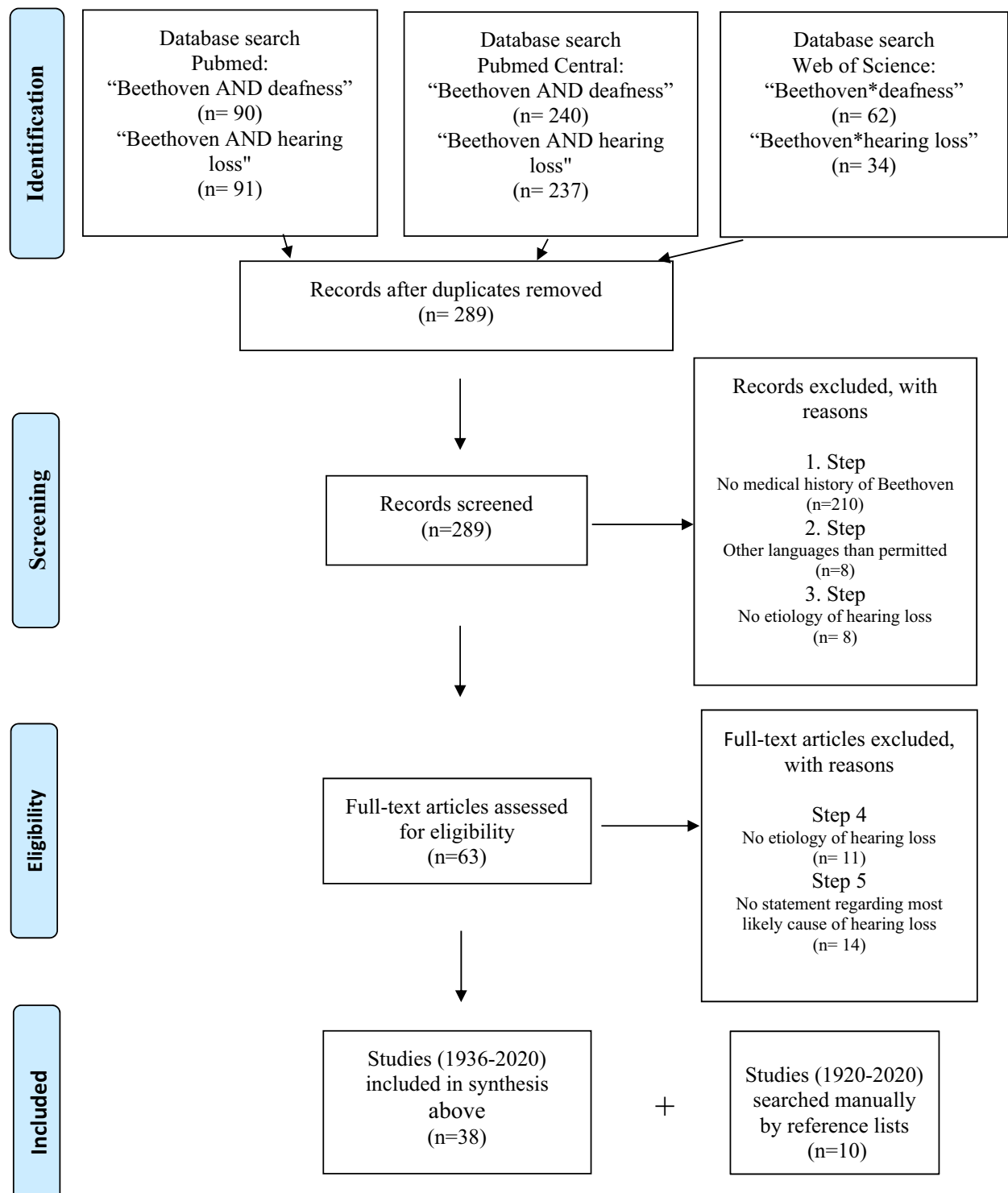

The number of the most likely supposed cause of Beethoven's hearing loss is shown in Fig. 3 according to each author group. To prevent distortion of the results, the most likely diagnoses were counted only once for every author if the author had more than one publication. The four most frequent diagnoses were otosclerosis $(n=10)$, syphilis $(n=9)$, Paget's disease $(n=6)$ and neural deafness not otherwise specified $(n=5)$.

\section{Discussion}

Even 250 years after Ludwig van Beethoven's birth, medics still deal with the cause of his deafness which is still obscure. We are presenting the first systematic review of medical publications on the most likely cause of Ludwig van Beethoven's deafness. Over the past 100 years, there was a mean release frequency of about one new publication supposing an underlying aetiology of his hearing loss in the medical literature in every 2.1 years with a quite continuous publication activity except for the period during and after the Second World War.

Regarding the subspecialities of the authors, there is an obvious change in the publications on this topic over the past 100 years. Whereas from 1920 to 1970, otolaryngologists represented the dominating discipline with 14 of 21 publications, in the past 50 years only 4 of 21 author groups originate from otolaryngology. So, experts from different disciplines like pharmacologists, pathologists, infectiologists, gastroenterologists, rheumatologists, neurologists, 
Table 1 Chronological order of medical publications (1920-2020) dealing with the most likely cause of the hearing loss of L

\begin{tabular}{|c|c|c|c|c|}
\hline Year of publication & Authors & Type of article & $\begin{array}{l}\text { Medical specialty } \\
\text { of the author }\end{array}$ & Most likely etiology \\
\hline 2020 & Brotto D et al. & $\mathrm{O} / \mathrm{R}$ & ORL & Chronic lead poisoning \\
\hline 2018 & Pedro MKF et al. & $\mathrm{HN}$ & Neurology & Syphilis \\
\hline 2018 & McGill IK and Agius MA & $\mathrm{CF}$ & Psychiatry & Tertiary syphilis \\
\hline 2017 & Oiseth SJ & $\mathrm{O} / \mathrm{R}$ & Pathology & Paget's disease \\
\hline 2013 & Stevens MH et al. & $\mathrm{O} / \mathrm{R}$ & ORL & Chronic lead exposure \\
\hline 2008 & Domic D and Payá E & $\mathrm{HN}$ & Infectiology & Syphilis \\
\hline 2005 & Karmody CS and Bachor ES & $\mathrm{O} / \mathrm{R}$ & ORL & Immunopathy with IBD \\
\hline $2001 / 00$ & Huxtable RJ & $\mathrm{HN} / \mathrm{O} / \mathrm{R}$ & Pharmacology & Neural deafness nos \\
\hline 2001 & Wolf P & $\mathrm{HN}$ & Pathology & Paget's disease \\
\hline 2000 & Donnenberg MS et al. & $\mathrm{O} / \mathrm{R}$ & Infectiology & Syphilis \\
\hline 1996 & Kubba AK and Young M & $\mathrm{O} / \mathrm{R}$ & Gastroenterology & Mixture nerve deafness and otosclerosis \\
\hline 1994/92/90 & Palferman TG & $\mathrm{O} / \mathrm{R} / \mathrm{LE} / \mathrm{HN}$ & Rheumatology & Sarcoidosis \\
\hline 1994 & Drake ME & $\mathrm{HN}$ & Neurology & Sarcoidosis \\
\hline 1992 & Wintersgill P & $\mathrm{HN}$ & Medicine & Otosclerosis \\
\hline 1990 & Shearer PD & $\mathrm{O} / \mathrm{R}$ & Pediatrics & Cochlear otosclerosis \\
\hline 1988/1995 & Davies PJ & $\mathrm{O} / \mathrm{R} / \mathrm{O} / \mathrm{R}$ & Gastroenterology & Immunopathy with IBD \\
\hline 1986 & Jesserer $\mathrm{H}$ and Bankl $\mathrm{H}$ & $\mathrm{O} / \mathrm{R}$ & Pathology & Exclusion of Paget's disease \\
\hline 1978 & Landsberger $\mathrm{M}$ & $\mathrm{O} / \mathrm{R}$ & Pediatrics & Otosclerosis \\
\hline 1974 & Sellars SL & $\mathrm{HN}$ & ORL & Otosclerosis, ostitis deformans \\
\hline $1971 / 71$ & Naiken VS & $\mathrm{O} / \mathrm{R} / \mathrm{LE}$ & Pathology & Paget's disease \\
\hline $1971 / 70$ & Larkin E & $\mathrm{EN} / \mathrm{HN}$ & Neurology & Connective tissue disorder, SLE \\
\hline 1970 & Kerner D & $\mathrm{O} / \mathrm{R}$ & Medicine & Syphilis \\
\hline 1970 & Miller JW & LE & Unknown & Trauma of cochlea and acoustic nerve \\
\hline 1970 & Stevens KM and Hemenway WG & $\mathrm{HN}$ & ORL & Cochlear otosclerosis \\
\hline 1965 & Coude Jahn F & $\mathrm{O} / \mathrm{R}$ & ORL & Otosclerosis \\
\hline 1965 & Asherton $\mathrm{N}$ & $\mathrm{HN}$ & ORL & Pagets disease \\
\hline 1963 & Sellers LM & $\mathrm{O} / \mathrm{R}$ & ORL & Neurovascular hearing loss \\
\hline 1960 & Cawthorne $\mathrm{T}$ & $\mathrm{O} / \mathrm{R}$ & ORL & Otosclerosis \\
\hline 1958 & McCabe BF & $\mathrm{O} / \mathrm{R}$ & ORL & Syphilis \\
\hline 1937 & Squires PC & $\mathrm{O} / \mathrm{R}$ & Psychiatry & Acquired syphilis \\
\hline 1937 & Magenau C & $\mathrm{O} / \mathrm{R}$ & ORL & Inner ear disease nos \\
\hline 1936 & Vorhees IW & $\mathrm{O} / \mathrm{R}$ & ORL & Syphilis \\
\hline 1935 & Frank I & $\mathrm{O} / \mathrm{R}$ & ORL & Otosclerosis \\
\hline 1934 & J I S & $\mathrm{HN}$ & Unknown & Otosclerosis and nerve deafness \\
\hline 1932 & Tremble E & $\mathrm{O} / \mathrm{R}$ & ORL & Nerve affection by gastrointestinal disturbances \\
\hline 1930 & Sorsby M & $\mathrm{O} / \mathrm{R}$ & ORL & Exclusion of syphilis \\
\hline 1928 & Schultze F & $\mathrm{O} / \mathrm{R}$ & Neurology & Nerval deafness not necessarily caused by syphilis \\
\hline 1928 & Marage M & $\mathrm{O} / \mathrm{R}$ & ORL & Labyrinthitis due to cerebral or intestinal cause \\
\hline 1927 & Jacobsohn J & $\mathrm{HN}$ & Neurology & Syphilis \\
\hline 1927 & Neumann $\mathrm{H}$ & $\mathrm{O} / \mathrm{R}$ & ORL & Paget's disease or otosclerosis \\
\hline 1921 & Gradenigo G & $\mathrm{O} / \mathrm{R}$ & ORL & Otosclerosis \\
\hline 1920 & Schweisheimer W & $\mathrm{O} / \mathrm{R}$ & Unknown & Neuritis acoustica \\
\hline
\end{tabular}

Beethoven $(O / R$ Original or Review Article, $H N$ historical note, $C F$ conference paper, $E N$ editorial note, $L E$ letter to the editor, $I B D$ inflammatory bowel disease, nos not otherwise specified) 
Fig. 3 Frequencies of the supposed most likely causes of the hearing loss of Beethoven according to the number of author groups in the medical literature 1920-2020 (SLE systemic lupus erythematosus, $I B D$ inflammatory bowel disease, nos not otherwise specified)

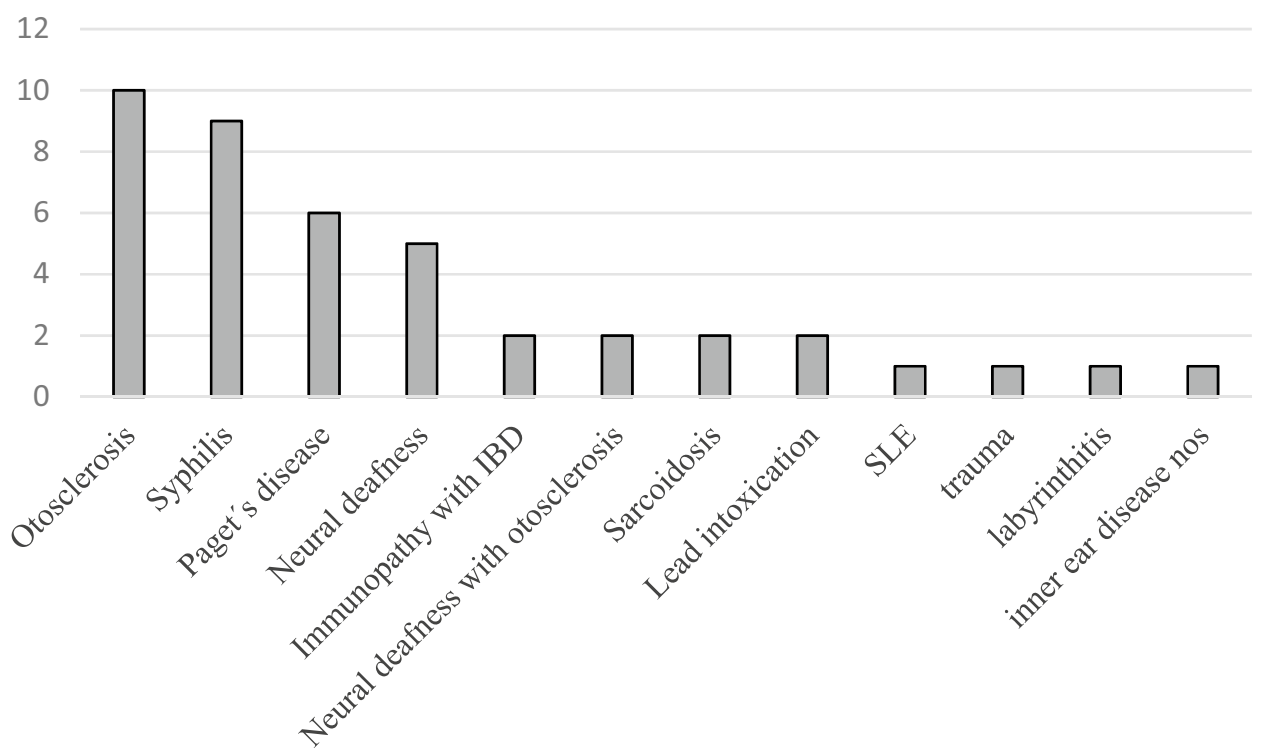

psychiatrics and even paediatricians might be increasingly interested in this topic.

In the literature, several differential diagnoses regarding the aetiology of Beethoven's hearing loss have been controversially discussed. According to the number of publications, the leading cause supposed to explain Beethoven's hearing loss is otosclerosis which was already favoured in the medical literature between 1921 and 1935 by otolaryngologists $[14,15]$ and later in the 1970 s and 1990 s by a wide range of authors of different medical specialities [16, 17]. Arguments supporting this diagnosis have been the age when Beethoven first experienced symptoms of hearing loss in his mid-twenties and the progressive decline of his hearing affecting both ears. In addition, some authors diagnosed conductive hearing loss in Beethoven based on a wooden drumstick that Beethoven applied to the piano and held on the other side between his teeth which is comparable to a bone conduction hearing aid. However, the only description of such a drumstick was done by the French physician J.A.A. Rattel, who was not a contemporary of Beethoven. Thus, the mentioned sort of conductive hearing aid might be classified more legendary than real nowadays [18]. In contrast, the medical history of Beethoven with a hearing impairment initially involving the high frequencies, a loss of discrimination, and signs of a positive recruitment is not typical in early stages of a fenestral otosclerosis, but point more to a cochlear hearing impairment. So, combined or cochlear otosclerosis might be a justifiable alternative differential diagnosis as mentioned by Shearer [17]. In the postmortem protocol of Beethoven, no otosclerotic involvement of the oval window was reported, although this might easily have been visible even without a microscope according to Sorsby who excluded a combined otosclerosis [19]. The remaining pure cochlear otosclerosis is defined as a focus of otosclerosis located in the otic capsule involving the cochlear endosteum, causing sensorineural hearing loss without any stapes fixation. However, the prevalence of pure cochlear otosclerosis might be low even if the current data situation is still unclear. Whereas clinical-radiological studies report patients with a pure cochlear sensorineural type of otosclerosis [20], otopathologic studies indicate that this type of pathology is very rare with a prevalence of only $1 \%$ of all patients with otosclerosis [21]. According to these data, Beethoven would have suffered from a very rare sub-entity of otosclerosis if cochlear otosclerosis was the underlying cause of his hearing impairment.

Syphilis is the aetiology second most accused of being the cause of Beethoven's hearing loss. In the nineteenth century, syphilis was a very common venereal infectious disease which was considered the cause of Beethoven's deafness by several non-medical authors and the composer's biographers. The non-physician G. Grove was the first who mentioned this in the first edition of his musicology dictionary "Grove's dictionary of Music and Musicians" in 1879 by the entry "the whole of these [postmortem] appearances are most probably the result of syphilitic affections at an early period of his life". This statement had been initiated by third-hand information of the biographer A. W. Thayer who assumed Beethoven had syphilis based on two prescriptions for Beethoven by his physician Dr. Bertolini in 1820 for medication containing mercury [22]. Even in the 1920s and 1930s, some authors still favoured the hypothesis of tertiary syphilis as the cause of his hearing loss [23]. However, in 1930 the otolaryngologist Sorsby published arguments against syphilis as the cause of Beethoven's hearing loss. He stated that no sudden onset or sudden total deafness or vertigo or nystagmus as commonly seen in syphilis patients had been described in Beethoven's medical history [19]. 
So, in the following decades syphilis was only sporadically mentioned [24], and Shearer mentioned even in 1990 that McCabe was still the only modern otologist who defended the aetiology of syphilis [17, 24]. Even if a tertiary syphilis might explain the mentioned atrophy of the cochlear nerve due to meningeal irritation, and even if an uveitis as an inflammatory ocular disease might be part of a neurosyphilis complex, there were no other signs of advanced syphilis such as headache, hemiplegia, dysphasia and seizures and no autoptic evidence as gumma and tabes dorsalis. Also, the early beginning of the hearing loss at the age of 26 years is unlikely in tertiary neurosyphilis, and the pace of progression of the hearing impairment is different from the pace of progression in meningovascular syphilis patients [25]. In addition to the missing typical anamnestic and autoptic findings regarding the signs of syphilis in Beethoven, a more recent examination of a ringlet of the composer in 2000 demonstrated that there was no detectable mercury in Beethoven's hair which makes syphilis therapy with mercury unlikely [26]. In opposition to these arguments against syphilis as the cause of Beethoven's hearing impairment, the syphilis diagnosis has gained interest again in the medical literature of the twenty-first century by up to now four authors with medical specialization in infectiology, neurology, and psychiatry favouring this aetiology anew [27-30]. Overall, syphilis is still one of the aetiologies which has most often been accused of being the cause of Beethoven's hearing loss by medical publishers over the past 100 years. However, in the literature published by otolaryngologists, this differential diagnosis has not been favoured any more during the last 50 years even if nowadays the diagnosis of otosyphilis still needs to be considered in the differential diagnostic mind of the clinical otologists as recently mentioned by Theeuwen [31].

Besides otosclerosis, another bone-remodelling disease with fixation of the stapes, the Paget's disease, was accused of being the cause of Beethoven's deafness in perennial publications from 1965 up to these days [32, 33]. About $50 \%$ of patients with Paget's disease are known to suffer from hearing loss which can be caused by multiple mechanisms including, e.g., a fixation of the stapes footplate, a diminished mineral density of the cochlear capsule with microfractures and a damage of the cochlear nerve by a bony overgrowth and compression in tiny foramina before and within the internal auditory canal [33]. The authors supporting this hypothesis based their argumentation on the report that the dense skull was twice as thick as normal and on the documentation of a narrowed bony part of the Eustachian tube in the autopsy protocol of Beethoven as well as on Beethoven's facial characteristics such as his big head and jaw. Furthermore, an atrophy of the cochlear nerve which was mentioned in the autopsy protocol and Beethoven's statement that he completely lost his ability to hear after a fall in 1815 [8] were appraised as secondary clues for an underlying Paget's disease. In addition, an increased blood supply and hyperplasia of the vessels of the temporal bones as mentioned in the autopsy protocol of Beethoven can also be seen in patients with Paget's disease. However, only $3 \%$ of patients with Paget's disease present symptoms under the age of 30 years [34], and in most cases hearing impairment initially starts with either a mixed or a conductive hearing loss affecting mostly the lower frequencies in contrast to Beethoven who presented with a hearing loss in the high frequencies. In addition, in 1986 the pathologists Jesserer and Bankl examined parietal bone fragments of the skull of Beethoven without finding any macropathological or radiological signs of Paget's disease. Bilateral involvement of the temporal bones by osteodystrophic changes in the mid-twenties without any inclusion of the adjacent parietal parts up to the fifth decade of life have to be considered as quite unlikely [5].

From 1920 up to the turn of the millennium, neural deafness was periodically accused of being the underlying cause of Beethoven's hearing impairment $[35,36]$. This assumption was mainly based on the fact that the atrophy of the cochlear nerves which was described could not entirely be explained by any other aetiology. However, a convincing pathophysiologic cause was not answered by these publications [35, 37]. Furthermore, the anamnestic cues of a positive recruitment by Beethoven himself are not compatible with the hypothesis of a neural origin, but rather point more towards a cochlear hearing impairment.

Beethoven himself assumed a relationship between his lifelong gastrointestinal problems and his hearing impairment. This is also reflected throughout the medical literature during the last 100 years. While assumptions about a toxic labyrinthitis or an unspecified cochlear nerve disorder caused by intestinal problems which were popular in the 1920s and 1930s [37, 38] are no longer tenable today, the assumption of an inflammatory bowel disease (IBD) associated with an immunopathy of the inner ear was first expressed by Davies in 1988 and elaborated later by Karmody in 2005 [40]. This goes in line with the first description of an autoimmune sensorineural hearing loss by McCabe in 1979 [39-41]. Several authors attributed Beethoven's intestinal disorder to ulcerative colitis [42] or more rarely to Crohn's disease [43] which are subsets of IBD. Especially in ulcerative colitis, an autoimmunemediated sensorineural hearing loss might become an extraintestinal manifestation of an IBD [44] and an underlying ulcerative colitis also might explain other maladies of Beethoven such as joint pains, facial rash, and uveitis [40]. However, up to now research regarding extraintestinal otologic manifestations of ulcerative colitis is rare and the prevalence of a profound hearing loss as a consequence of an IBD has not yet been clarified. One argument against 
the hypothesis of an autoimmune-mediated sensorineural hearing loss is the period of appearance of Beethoven's hearing impairment; an autoimmune-mediated hearing loss usually occurs during weeks or months but not years as it was the case with Beethoven [45]. In addition, according to the primary literature there was no history of rectal bleeding during his lifetime and the autopsy protocol revealed an intestinal tract filled with air and without adhesions, strictures, or perforations. This strongly argues against the hypothesis that Beethoven suffered from IBD at all [46].

In the 1990s, Drake and Palverman favoured independently of each other sarcoidosis as a diagnosis, as sarcoidosis encompasses most of the different diseases that Beethoven had. The multisystemic involvement of sarcoidosis can cause chronic active hepatitis followed by cirrhosis, inflammatory bowel disease, post-dysenteric seronegative arthropathy, hypercalcemia, and nephrolithiasis [47]. In 5\% of subjects with sarcoidosis, the nervous system is involved. Neurosarcoidosis might explain Beethoven's deafness [48]. But although bilateral auditory nerve deafness has been reported in sarcoidosis, this is associated with a thickening but not with an atrophy of the cochlear nerves as it was described in Beethoven's autopsy protocol. In addition, neurosarcoidosis usually encompasses a clinical involvement of the facial nerve which was not found in Beethoven. Not least, no gross pathology of lung and heart was mentioned in his autopsy protocol.

It lasted up to 2013, that lead intoxication was mentioned in the medical literature as a potential cause of Beethoven's hearing loss. Evaluations of Beethoven's hair and parietal skull bones in the first decade of this century revealed substantially elevated lead levels indicating chronic lead exposure which might have caused lead poisoning [6,7]. Whereas subacute lead poisoning notoriously induces a motor neurone disorder, long-term lead exposure can result in a slowly progressive high-frequency hearing loss [49] probably caused by axonal degeneration of the cochlear nerve. Stevens explained a chronic lead exposure of Beethoven by his long-lasting consumption of wine, which might have started at the age of 17 after the death of his mother. At that time, lead was added to improve the flavour of cheaper wines like the Hungarian ones preferred by Beethoven [45]. Other sequelae of chronic lead intoxication such as abdominal colic, hepatotoxicity, and kidney damage as reported by Beethoven support this hypothesis. Recently, Brotto underlined this hypothesis with regard to Beethoven's autoptic findings of wrinkled cochlear nerves that lacked pith without a medulla [50]. However, up to now the scientific data regarding the prevalence and extent of hearing loss induced by chronic lead exposure is still rare. Therefore, it remains difficult to clearly associate Beethoven's hearing impairment with a chronic exposure of lead.

\section{Conclusion}

Beethoven's explicit wish to clarify the cause of his deafness after his death has been fulfilled in numerous medical publications. Based on primary historical sources including the autopsy report and more recent investigations of probes of his skull and hair, several different hypotheses on the aetiology of the hearing impairment of Beethoven have been postulated.

Otosclerosis and syphilis have been the predominant supposed causes in the medical literature of the past 100 years, whereby the long-rejected hypothesis of syphilis has shown a surprising and probably questionable revival during the last 20 years. In addition to numerous other causes, the hypothesis of a chronic lead intoxication has recently been developed in the medical literature over the past decade.

To date, no single aetiology exists which might on its own completely explain Ludwig van Beethoven's hearing impairment without a pertinent argument against this hypothesis. So, it is most likely that the question regarding the irrevocable cause of his deafness will probably remain unanswered forever.

Whereas during his lifetime only insufficient hearing rehabilitation via hearing aids in the form of ear trumpets and a resonating plate was available, it is supposed that Beethoven would now probably benefit from an electrical stimulation by a cochlear implant. In this context, it has to be mentioned that the composer anticipated the physical fundamentals of this therapeutic option already at the beginning of his hearing loss when he wrote in 1801: "I hear wonders of galvanism; what do you say to it? A physician told me that he knew a deaf and dumb child whose hearing was restored by it, and likewise a man who had been deaf for seven years, and recovered his hearing" [8]. To predict the outcome of such a treatment, the irrevocable identification of the aetiology of his hearing loss-especially regarding the possible neural pathophysiologic cause-would be of therapeutic importance.

Acknowledgements This article is dedicated to my father Dr. Günter Thomas, who initiated my interest in the medical history of musicians' diseases (JPT).

Funding Open Access funding enabled and organized by Projekt DEAL.

\section{Compliance with ethical standards}

Conflict of interest The authors declare that they have no conflict of interest.

Human and animals The research does not involve human participants and/or animals.

Informed consent Not applicable. 
Open Access This article is licensed under a Creative Commons Attribution 4.0 International License, which permits use, sharing, adaptation, distribution and reproduction in any medium or format, as long as you give appropriate credit to the original author(s) and the source, provide a link to the Creative Commons licence, and indicate if changes were made. The images or other third party material in this article are included in the article's Creative Commons licence, unless indicated otherwise in a credit line to the material. If material is not included in the article's Creative Commons licence and your intended use is not permitted by statutory regulation or exceeds the permitted use, you will need to obtain permission directly from the copyright holder. To view a copy of this licence, visit http://creativecommons.org/licenses/by/4.0/.

\section{References}

1. Liston SL, Yanz JL, Preves D et al (1989) Beethoven's deafness. Laryngoscope 99:1301-1304

2. Saccenti ES, Smilde AK, Saris WHM (2011) Beethoven's deafness and his three styles. BMJ 343:7589

3. Wainapel SF (1995) Ludwig van Beethoven - the influence of hearing- loss on his musical development. Med Probl Perform Artists 10(3):90-93

4. Harrison $P$ (1988) The effects of deafness on musical composition. J R Soc Med 81(10):598-601

5. Jesserer H, Bankl H (1986) Was Beethoven's deafness caused by Paget's disease? Report of findings and study of skull fragments of Ludwig van Beethoven. LRO 65(10):592-597

6. U.S Department of Energy (2005) New release of the argonne national laboratory. argonne researchers confirm lead as cause of Beethoven's Illness. https://www.sciencedaily.com/relea ses/2005/12/051207211035.htm. (Accessed 6 Dec 2005)

7. U.S Department of Energy (2000) New Release of the argonne national laboratory. research proves Beethoven suffered from lead poisoning. https://www.Anl.gov/OPA/whatsnew/Beethovenstory. Htm. (Accessed 17 Oct 2000)

8. Kalischer AC (2014) Beethoven's letters. Cambridge University Press, Cambridge

9. Schindler A (1973) Ludwig van Beethoven. Reclam Leipzig, Leipzig

10. Thayer AW (1970) Ludwig van Beethovens Leben. Olms Hildesheim, Hildesheim

11. Breuning G (1874) Aus dem Schwarzspanierhause. Erinnerungen an L. van Beethoven aus meiner Jugendzeit, Rosner Wien

12. Weißenbach A (1816) Meine Reise zum Kongreß in Wien. Wahrheit und Dichtung. J. B, Walkishauser Wien

13. Moher D, Liberati A, Tetzlaff J, Altman DG (2009) Preferred Reporting Itmes for systematic reviews and meta-analyses: the PRISMA statement. PLoS Med 6(7):e1000097

14. Gradenigo G (1921) La sordità di Beethoven. Arch Ital Otol $1: 221-226$

15. Frank I (1935) The deafness of Beethoven. Ann Otol Rhinol Laryngol 44:327-336

16. Sellars SL (1974) Beethoven's deafness S. Afr med J 48:1585-1588

17. Shearer PD (1990) The deafness of Beethoven: an audiologic and medical overview. Am J Otol 11(5):370-374

18. Perciaccante A, Coralli A, Bauman NG (2020) Beethoven: his hearing loss and his hearing aids. Otol Neurotol. https://doi. org/10.1097/MAO.0000000000002755

19. Sorsby M (1930) Beethoven's deafness. J Laryngol Otol 45:329-343

20. Diaz RC (2008) Cochlear otosclerosis. Otol Neurotol 29(5):723-724
21. Schuknecht HF, Kirchner JC (1974) Cochlear otosclerosis: fact or fantasy. Laryngoscope 84:766-782

22. Grove G (1880) Dictionary of Music and Musicians. Macmillan London, London

23. Jacobsohn J (1927) Beethovens Gehörleiden und letzte Krankheit. Deutsch med Wochenschr 53:6110

24. McCabe BF (1958) Beethoven's deafness. Ann Otol Rhinol Laryngol 113:511-525

25. Palferman TG (1992) Beethoven. J R Coll Phys Lon 26:112-114

26. Martin R (2000) Beethoven's hair. Broadway Books, New York

27. Donnenberg MS, Collins MT, Benitez RM et al (2000) The sound that failed. Am J Med 108:475-480

28. Domic DT, Paya EG (2005) Treponema pallidum and Ludwig van Beethoven's deafness. Rev Chil Infect 25(4):294

29. McGill I, Agius M (2018) Tertiary syphilis (General paralysis of the insane) and bipolar disorder, the role of these two disorders in the life of famous composers. Psychiatria Danubina 30(Suppl 7):563-566

30. Pedro MKF, Germiniani FMB, Teive HAG (2018) Neurosyphilis and classical music: the great composers and "the great imitator." Arq Neuropsiquiatr 76(11):791-794

31. Theeuwen H, Whipple M, Litvack JR (2019) Otosyphilis: resurgence of an old disease. Laryngoscope 129(7):1680-1684

32. Asherton N (1965) The deafness of Beethoven and the saga of the stapes. Hunterian Soc 24:7-24

33. Oiseth SJ (2017) Beethoven's autopsy revisited: a pathologist sounds a final note. J Med Biogr 25(3):139-147

34. Gutman AB, Kasabach H (1936) Paget's disease: analysis of 116 cases. Am J Med Scien 191:2361-2381

35. Schweisheimer W (1920) Beethovens Krankheiten. Münchener Med Wochenschr IXVI I: 1473

36. Huxtable RJ (2000) The deafness of Beethoven: a paradigm of hearing problems. Proc West Pharm Soc 43:1-8

37. Tremble E (1932) The deafness of Beethoven. Can Med Assoc J 27(5):546-549

38. Marage M (1928) Nature de la surdité de Beethoven. Compt Rend Acad d Sci 186:110-112

39. Davies PJ (1988) Beethoven's deafness - a new theory. Med J Austr 149(11-12):644-649

40. Karmody CS, Bachor ES (2005) The deafness of Ludwig van Beethoven: an immunopathy. Otol Neurotol 26:809-814

41. McCabe BF (1979) Autoimmune sensorineural hearing loss. Ann Otol 88:585-589

42. Sellers LM (1963) Beethoven the immortal: his deafness and his music. Laryngoscope 73:1158-1183

43. Critchley M, Henson RA (eds) (1977) Music and the brain: studies in the neurology of music. William Heinemann London, London

44. Fousekis FS, Saridi M, Albani E et al (2018) Ear involvement in inflammatory bowel disease: a review of the literature. J Clin Med Res 10(8):609-614

45. Stevens MH, Jacobsen T, Crofts AK (2013) Lead and the deafness of Ludwig van Beethoven. Laryngoscope 123(11):2854-2858

46. Kubba AK, Young M (1996) Ludwig van Beethoven: a medical biography. Lancet 347:167-170

47. Palferman TG (1994) Beethoven: medicine, music, and myths. Int J Dermatol 33(9):664-671

48. Drake ME (1994) Deafness, dysesthesia, depression, diarrhea dropsy, and death: the case of sarcoidosis in Ludwig van Beethoven. Neurology 44:562-565

49. Cohen SM (2001) Lead poisoning: a summary of treatment and prevention. Pediatr Nurs 27(29):125-126

50. Brotto D, Fellin R, Sorrentino F, Gheller F, Trevisi P, Bovo R (2020) A modern case sheds light on a classical enigma: Beethoven's deafness. Laryngoscope. https://doi.org/10.1002/lary.28464

Publisher's Note Springer Nature remains neutral with regard to jurisdictional claims in published maps and institutional affiliations. 